$08.1 ; 08.2$

\title{
Синтез методом молекулярно-пучковой эпитаксии и свойства наноструктур InGaN разветвленной морфологии на кремниевой подложке
}

\author{
(C) Р.Р. Резник ${ }^{1}$, К.П. Котляр ${ }^{2}$, Н.В. Крыжановская ${ }^{2}$, С.В. Морозов ${ }^{3,4}$, Г.Э. Цырлин ${ }^{1,2.5-7}$ \\ ${ }^{1}$ Санкт-Петербургский национальный исследовательский университет информационных технологий, механики и оптики \\ (Университет ИТМО), Санкт-Петербург, Россия \\ ${ }^{2}$ Санкт-Петербургский национальный исследовательский Академический университет РАН, Санкт-Петербург, Россия \\ ${ }^{3}$ Институт фозики микроструктур РАН, Нижний Новгород, Россия \\ ${ }^{4}$ Нижегородский государственный университет им. Н.И. Лобачевского, Нижний Новгород, Россия \\ ${ }^{5}$ Институт аналитического приборостроения РАН, Санкт-Петербург, Россия \\ ${ }^{6}$ Санкт-Петербургский политехнический университет им. Петра Великого, Санкт-Петербург, Россия \\ ${ }^{7}$ Санкт-Петербургский государственный электротехнический университет „ЛЭТИ“, Санкт-Петербург, Россия \\ E-mail: moment92@mail.ru
}

Поступило в Редакцию 11 июля 2019г.

В окончательной редакции 18 июля 2019 г.

Принято к публикации 18 июля 2019г.

\begin{abstract}
Продемонстрирована принципиальная возможность синтеза наноструктур InGaN разветвленной морфологии („наноцветов“) методом молекулярно-пучковой эпитаксии на поверхности подложки кремния. Результаты морфологических исследований показали, что развитие морфологии наноструктур InGaN происходит в несколько этапов даже при поддержании неизменной температуры подложки. Выращенные структуры демонстрируют линию фотолюминесценции в широком диапазоне длин волн от 450 до $950 \mathrm{~nm}$ при комнатной температуре.
\end{abstract}

Ключевые слова: нитридные наноструктуры, кремний, молекулярно-пучковая эпитаксия, полупроводники, оптоэлектроника.

DOI: 10.21883/PJTF.2019.21.48475.17975

В настоящее время полупроводниковые соединения нитридов металлов III группы благодаря своим уникальным свойствам вызывают повышенный интерес для современной оптоэлектроники [1]. В частности, тройные соединения InGaN являются перспективными для создания приборов, излучающих в видимой области спектра [2]. Интерес к получению таких структур обусловлен в том числе перспективами интеграции полупроводников III-N и кремниевой электроники, возможностью использования подложек больших (до 150-200 mm) размеров, их низкой стоимостью, хорошей электрической проводимостью, а также получением „template“ структур. Однако синтез качественных прямозонных двумерных слоев InGaN на кремниевых подложках затруднен ввиду значительного различия постоянных решеток и коэффициентов термического расширения, что является причиной возникновения высокой плотности дефектов различной природы в слое InGaN. Для успешного решения этих проблем прилагаются значительные усилия. В частности, для подавления процесса возникновения дислокаций несоответствия и снижения количества дефектов в эпитаксиальном полупроводниковом нитридном слое формируют барьерные промежуточные слои $\{\mathrm{SiC} / \mathrm{Si}(111), \mathrm{AlNGaN} / \mathrm{SiC} / \mathrm{Si}(111)$ и $\mathrm{GaN} / \mathrm{AlN}-\mathrm{GaN} / \mathrm{SiC} / \mathrm{Si}(111)\} \quad[3,4]$. Однако такой подход способствует снижению эффективности или вообще невозможности создания приборов на основе InGaN.
Вместе с тем весьма перспективным является альтернативный путь преодоления проблемы - синтез непланарных наноструктур In GaN сложной формы на поверхности кремниевой подложки. Благодаря развитой морфологии механические напряжения в полупроводниковых наноструктурах, вызванные различием постоянных решеток и коэффициентов термического расширения, релаксируют, и количество дефектов значительно уменьшается [5]. В работе [6] были предприняты попытки синтеза методом молекулярно-пучковой эпитаксии нитридных наноструктур развитой морфологии для оптических приложений видимого диапазона. Однако синтезировать структуры на основе InGaN/GaN удалось только с использованием многоступенчатых процедур, включающих в себя прокисление кремния, создание маски для травления, травление в плазме $\mathrm{SF}_{6}$ и удаление маски в плавиковой кислоте для создания отверстий для синтеза наноструктур. Такой процесс подготовки поверхности кремния для последующего роста является дорогостоящим и времязатратным.

В настоящей работе приведены результаты комплекса экспериментальных процедур по синтезу методом молекулярно-пучковой эпитаксии и изучению морфологических и оптических свойств наноструктур InGaN разветвленной морфологии (по виду напоминающих „наноцветы“, НЦ) непосредственно на поверхности кремния.

Эксперименты по синтезу НЦ InGaN проводились с помощью установки молекулярно-пучковой эпитаксии 

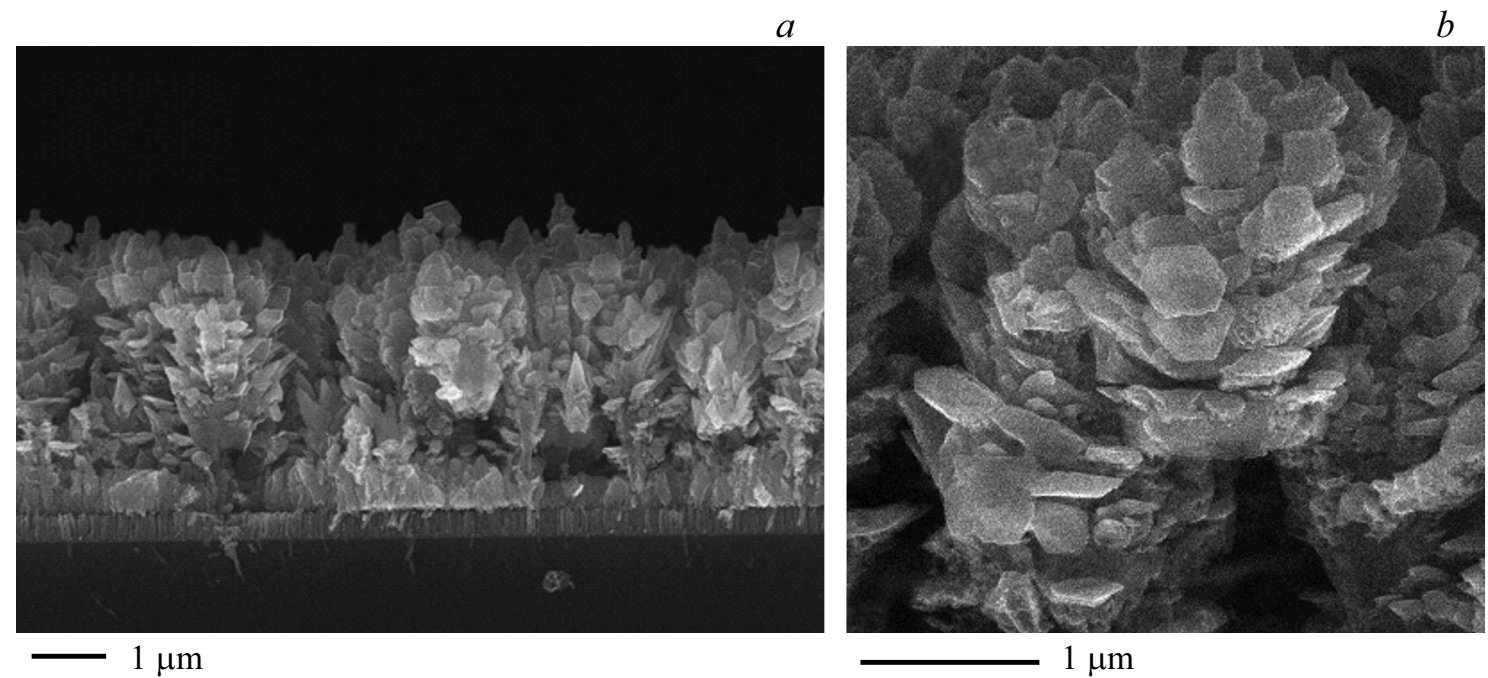

Рис. 1. $a$ - типичное РЭМ-изображение „наноцветов“ InGaN, выращенных на подложке $\mathrm{Si}(111) ; b$ - типичное РЭМ-изображение поверхности одиночного „наноцветка“ $\mathrm{InGaN}$.

Compact 12 фирмы Riber, оснащенной эффузионными источниками галлия, индия и плазменным источником азота. В качестве подложек использовались пластины кремния ориентации (111), легированные бором. На первом этапе загруженная в ростовую камеру подложка нагревалась до $950^{\circ} \mathrm{C}$ для термической очистки. Давление в камере в этот момент составляло $7 \cdot 10^{-8}$ Torr. Затем температуру подложки понижали до $600^{\circ} \mathrm{C}$ и инициировали источник плазмы азота. Температура роста во время процесса не изменялась. После стабилизации температуры подложки одновременно открывались заслонки источников $\mathrm{Ga}$ и In. Потоки галлия и индия при синтезе НЦ InGaN были равны и составляли $1 \cdot 10^{-7}$ Torr. Рост НЦ InGaN длился $17 \mathrm{~h}$.

Для исследования поверхности во время проведения ростовых экспериментов (in situ) использовался метод дифракции быстрых электронов на отражение (ДБЭО). По изменениям картин ДБЭО было видно, что формирование наноструктур преимущественно в вюрцитной фазе начиналось уже после $60 \mathrm{~s}$ роста.

Исследования морфологических свойств синтезированных структур выполнялись с помощью растрового электронного микроскопа (РЭМ) Supra 25 Zeiss. Изучение оптических свойств синтезированных структур проводилось с помощью метода фотолюминесценции (ФЛ) при комнатной температуре. В качестве возбуждения использовалась вторая гармоника $(400 \mathrm{~nm})$ фемтосекундного лазера „Tsunami“ фирмы Spectra-Physics $(800 \mathrm{~nm}, 120 \mathrm{fs}, 80 \mathrm{MHz})$. Сигнал ФЛ измерялся с помощью спектрометра „Acton TriVista“ и регистрировался CCD фирмы Princeton Instruments. Кинетика ФЛ регистрировалась с помощью streak-камеры „Optoscop“ фирмы Optronis.

На рис. $1, a, b$ приведены типичные РЭМ-изображения НЦ InGaN, выращенных на кремниевой подложке. Из рисунка видно, что синтезированные наноструктуры $\mathrm{InGaN}$ обладают сильно развитой морфологией. Средняя высота выращенных структур составила $4 \mu \mathrm{m}$. Необходимо отметить, что, как видно из рисунка, НЦ InGaN синтезировались в несколько этапов: сначала сформировались наноколонки, затем переходный слой и, наконец, наноструктуры с более развитой морфологией. Вероятно, разные этапы роста соответствуют эффективно разной (несмотря на постоянство ее поддержания по термопарным измерениям) температуре на поверхности, которая уменьшается с увеличением высоты наноструктур. Это может быть связано с изменением коэффициента термического поглощения растущей структуры вследствие образования развитой поверхности $[7,8]$.

На рис. 2, a приведены спектры фотолюминесценции выращенного образца, полученные при комнатной температуре при различных мощностях оптического возбуждения. На спектре ФЛ наблюдается широкая полоса в спектральном диапазоне от 450 до $950 \mathrm{~nm}$, которая обусловлена излучением от НЦ InGaN. Максимум интенсивности спектра ФЛ находится вблизи $600 \mathrm{~nm}$. Таким образом, данные наноструктуры могут быть перспективными в качестве активной области для создания источников белого света на основе одной системы материалов. Мы предполагаем, что большая ширина линии ФЛ связана с изменением процентного соотношения In и $\mathrm{Ga}$ в твердом растворе, которое может быть вызвано, в частности, эффективным изменением температуры на поверхности во время роста. Этот факт открывает перспективы для контроля индекса цветопередачи источника белого света путем подбора температуры подложки в процессе осаждения материала.

На рис. 2, $b$ приведена зависимость интегральной интенсивности ФЛ от оптической мощности возбуждения синтезированной структуры. Как видно из рисунка, зависимость описывается линейной функцией вида $f=k x+b$, где $k \sim 0.95$. Рост интенсивности не насыщается плоть до мощности возбуждения $10 \mathrm{~mW}$. Такой характер зависимости указывает на высокое оптическое 

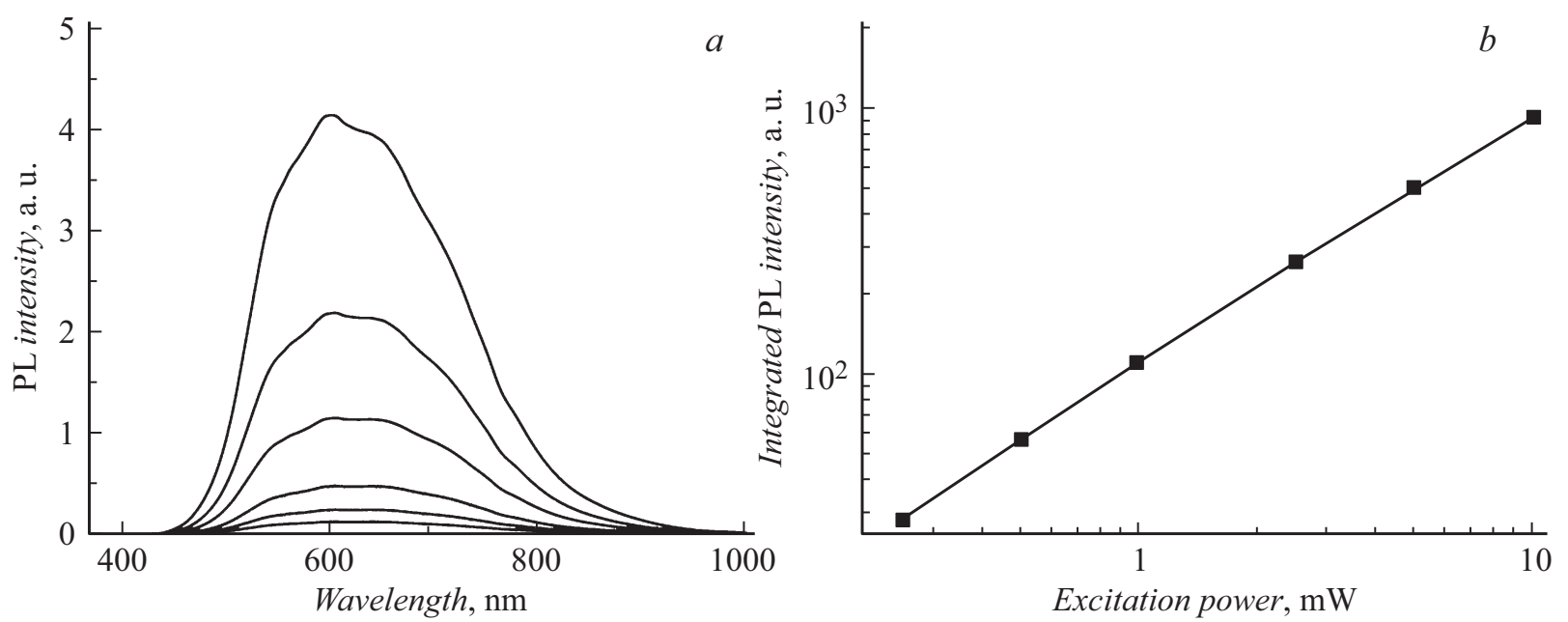

Рис. 2. $a-$ спектры ФЛ при комнатной температуре „наноцветов“ $\operatorname{InGaN}$, выращенных на подложке $\mathrm{Si}(111)$, измеренные при различной мощности оптического возбуждения. Спектры ФЛ соответствуют мощностям возбуждения $0.25,0.5,1,2.5,5$ и $10 \mathrm{~mW}$ (снизу вверх). $b$ - зависимость интегральной интенсивности ФЛ от мощности возбуждения „наноцветов“ InGaN. Tочки соответствуют экспериментальным данным, линия - результат линейной аппроксимации в двойном логарифмическом масштабе.

качество выращенных структур. Коэффициент наклона, близкий к единице, свидетельствует о слабой роли безызлучательной рекомбинации в структуре.

Таким образом, нами была продемонстрирована принципиальная возможность синтеза „наноцветов“ InGaN методом молекулярно-пучковой эпитаксии на поверхности подложки кремния. Разработанная технология роста позволяет синтезировать наноструктуры InGaN разветвленной морфологии без использования предростовых процедур подготовки поверхности, что способствует значительному снижению цены и времени на создание таких наноструктур. Результаты морфологических исследований показали, что рост происходит в несколько этапов. Выращенные структуры демонстрируют линию ФЛ в широком диапазоне длин волн от 450 до $950 \mathrm{~nm}$ при комнатной температуре. Все эти факты указывают на перспективность таких структур для оптических приложений, например для создания белых светодиодов на основе одного материала.

\section{Финансирование работы}

Работа выполнена при поддержке Российского научного фонда (проект № 19-72-30010). Синтез образцов проведен при финансовой поддержке Министерства науки и высшего образования РФ (в рамках выполнения госзадания № 16.2483.2017/4.6). Исследования оптических свойств синтезированных образцов осуществлены при поддержке Российского фонда фундаментальных исследований (проект № 16-29-03037-офи).

\section{Конфликт интересов}

Авторы заявляют, что у них нет конфликта интересов.

\section{Список литературы}

[1] Ambacher O. // J. Phys. D: Appl. Phys. 1998. V. 31. P. 2653 2710.

[2] Moustakas T.D., Iliopoulos E., Sampath A.V., Ng H.M., Doppalapudi D., Misra M., Korakakis D., Singh R. // J. Cryst. Growth. 2001. V. 227-228. P. 13-20.

[3] Бессолов В.Н., Ботнарюк В.М., Жиляев Ю.В., Коненкова Е.В., Полетаев Н.К., Раевский С.Д., Родин С.Н., Смирнов С.Л., Шарофидинов Ш., Щеглов М.П., Park H.S., Koike M. // Письма в ЖТФ. 2006. Т. 32. В.15. С. 60-66.

[4] Reznik R., Soshnikov I., Kukushkin S., Osipov A., Talalaev V., Cirlin G. // AIP Conf. Proc. 2019. V. 2064. P. 040004.

[5] Дубровский В.Г., Цырлин Г.Э., Устинов В.М. // ФТП. 2009. T. 43. B. 12. C. $1585-1628$.

[6] Hu F.R., Ochi K., Zhao Y., Hanea K. // Appl. Phys. Lett. 2006. V. 89. P. 171903.

[7] Glas F., Harmand J.-C. // Phys. Rev. B. 2006. V. 73. P. 155320.

[8] Сибирёв Н.В., Сошников И.П., Дубровский В.Г., Аршанский Е. // Письма в ЖТФ. 2006. Т. 32. В. 7. С. 28-35. 